ORIGINAL ARTICLE

\title{
Vaccination against hepatitis $B$ infection in patients with end stage renal disease
}

\author{
K Bel'eed, M Wright, D Eadington, M Farr, L Sellars
}

Postgrad Med J 2002;78:538-540

See end of article for authors' affiliations

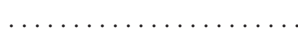

Correspondence to: Dr Khalid Bel'eed, Department of Renal Medicine, Hull Royal Infirmary, Hull HU3 2JZ, UK

khb0663@hotmail.com

Submitted

8 January 2002

Accepted 28 May 2002
Background: Experience of hepatitis B vaccination in a contemporary renal replacement programme is reported.

Methods: A total of 406 patients were involved: 214 on haemodialysis, 97 on continuous ambulatory peritoneal dialysis, 67 predialysis (serum creatinine $>400 \mu \mathrm{mol} / \mathrm{l}$ ), and 28 with a failing transplant. Primary vaccination comprised recombinant hepatitis $B$ vaccine (Engerix B) $40 \mu \mathrm{g}$ intramuscularly at 0 , 1,2 , and 3 months. Booster doses were administered three monthly if anti-HBs titre was $<100 \mathrm{IU} / \mathrm{l}$. Results: Uptake of vaccine was $61 \%$ (haemodialysis 70\%, continuous ambulatory peritoneal dialysis $62 \%$, predialysis $31 \%$, transplant $61 \%, p<0.0001$ ). Primary seroconversion occurred in $64 \%$ of vaccinated patients (anti-HBs; $10-100 \mathrm{U} / \mathrm{I}, 33 \%$; $>100 \mathrm{U} / \mathrm{I}, 31 \%$ ). Booster doses led to further improvement in immunity in 66/115 (57\%) patients after a first and $8 / 20(40 \%)$ patients after a second booster dose, but uptake was again poor (first booster $74 \%$, second $31 \%$ ). Seroprotection declined unexpectedly rapidly; after a mean of 16 months $71 / 115$ patients $(62 \%)$ had a significant fall in their anti-HBs titres; $30 / 115(26 \%)$ lost detectable antibody.

Conclusions: Routine hepatitis B vaccination of patients with end stage renal failure is logistically difficult to administer on a large scale; primary seroconversion is relatively poor, but improves after repeated booster doses; protective anti-HBs titres decline rapidly, and yearly antibody checks with selective booster doses will be required to maintain seroprotection. The cost effectiveness of a vaccination programme will vary greatly depending on the prevalence of hepatitis $B$ in the population at risk.
$\mathrm{H}$ epatitis B virus (HBV) infection has higher mortality and is more likely to result in a carrier state in uraemic patients. ${ }^{1-3}$ Infection control measures (universal precautions) introduced after HBV outbreaks in several UK dialysis units have been successful in minimising the risk of cross infection with HBV. The prevalence of hepatitis B surface antigen (HBsAg) in the UK dialysis population is now low $(0.4 \%)$, in contrast to other European countries. ${ }^{45}$ Vaccination against $\mathrm{HBV}$ is mandatory for dialysis staff, and the UK Renal Association recommends vaccination against HBV for all patients receiving renal replacement therapy or approaching end stage renal disease (ESRD). ${ }^{6}$

In January 1996 we identified a case of acute HBV infection in a patient on maintenance haemodialysis, the first case since the Hull unit opened in 1969. The patient, who was an intermittent intravenous drug user, had previously been HBsAg negative. The pattern of his seroconversion suggested approximately eight weeks between infection and clinical symptoms. He was dialysed in isolation, and universal precautions practised on the unit were continued without modification. Local discussion and wide consultation led to the decision to immediately vaccinate all patients with ESRD attending the unit, to reduce the risk of transmission if further cases were to occur. Two weekly HBsAg surveillance showed that no other patient treated on the unit after the estimated date of infection of the index case developed HBV infection or became HBsAg positive during the eight months up to August 1996, when we returned to our normal four monthly screening protocol.

\section{PATIENTS AND METHODS}

From March 1996 onwards we offered vaccination to all existing and new dialysis patients, and to predialysis and transplant patients with poor graft function (creatinine $>400$ $\mu \mathrm{mol} / \mathrm{l})$. The primary course of vaccine was $40 \mu \mathrm{g}$ of recombinant hepB vaccine (Engerix B, SmithKline Beecham) intramuscularly in the deltoid muscle at $0,1,2$, and 3 months, with the anti-HBs titre checked at six months. Anti-HBs titres were reported in four groups: > 100 IU/l, 10-100 IU/l, < 10 IU/l, and undetectable. Seroconversion was defined as an anti-HBs titre of $\geqslant 10 \mathrm{IU} / \mathrm{l}$. Booster doses were intended to be given every three months to patients not reaching the target anti-HBs titre of $>100 \mathrm{IU} / \mathrm{l}$, which offers the most complete protection against infection. ${ }^{78}$

There was extensive verbal and written explanation to the patients of the reasons for offering vaccination. Substantial logistic planning included outreach clinics to encourage compliance, with primary care involvement when geographically necessary. Monthly measures were made of serum creatinine, albumin, ferritin, and haemoglobin. Hepatitis B surface antibody was determined using the ELISA technique (Hepanostika anti-HBs, Organon Teknika, Boxtel, The Netherlands). Comparison between groups was by one way analysis of variance and $\chi^{2}$ test. Independent $t$ test was used to compare seroconverters and non-seroconverters. Statistical significance was $\mathrm{p}<0.05$.

\section{RESULTS}

Four hundred and six patients were targeted (table 1). Two hundred and forty seven patients (61\%) completed the primary vaccination course (haemodialysis 149 (70\%), continuous ambulatory peritoneal dialysis $60(62 \%)$, predialysis $21(31 \%)$, transplant $17(61 \%), p<0.0001)$. Causes for non-completion of the primary course included death, transfer to another unit, intercurrent illness, non-compliance,

Abbreviations: $E S R D$, end stage renal disease; $\mathrm{HBs} A g$; hepatitis $B$ surface antigen; $H B V$, hepatitis $B$ virus 
Table 1 Patients characteristics and uptake rates of primary vaccination course

\begin{tabular}{lllll}
\hline & $\begin{array}{l}\text { Haemodialysis } \\
(\mathrm{n}=214)\end{array}$ & $\begin{array}{l}\text { Peritoneal } \\
\text { dialysis }(\mathrm{n}=97)\end{array}$ & $\begin{array}{l}\text { Predialysis } \\
(\mathrm{n}=67)\end{array}$ & $\begin{array}{l}\text { Failing transplant } \\
(\mathrm{n}=28)\end{array}$ \\
\hline Mean (SD) age (years) & $59(16.7)$ & $52.6(16)$ & $60.5(10.6)$ & $37.7(15.9)$ \\
Gender (m/f) & $94 / 42$ & $34 / 21$ & $15 / 4$ & $10 / 7$ \\
Mean (SD) albumin (g/l) & $39.4(3.1)$ & $36.1(5.7)$ & $41.3(3.4)$ & $40.2(3)$ \\
Primary uptake (\%) & $149 / 214(70)$ & $60 / 97(62)$ & $21 / 67(31)$ & $17 / 28(61)$ \\
\hline
\end{tabular}

Table 2 Antibody titres after primary HBV vaccination; values are number (\%)

\begin{tabular}{llllll}
\hline $\begin{array}{l}\text { Anti-HBs titre } \\
(\mathrm{IU} / \mathrm{I})\end{array}$ & $\begin{array}{l}\text { Haemodialysis } \\
(\mathrm{n}=136)\end{array}$ & $\begin{array}{l}\text { Peritoneal } \\
\text { dialysis }(\mathrm{n}=55)\end{array}$ & $\begin{array}{l}\text { Predialysis } \\
(\mathrm{n}=19)\end{array}$ & $\begin{array}{l}\text { Failing renal } \\
\text { transplants }(\mathrm{n}=17)\end{array}$ & $\begin{array}{l}\text { Total } \\
(\mathrm{n}=227)\end{array}$ \\
\hline$>100$ & $47(34)$ & $14(26)$ & $8(42)$ & $2(12)$ & $71(31)$ \\
$10-100$ & $43(32)$ & $22(40)$ & $5(26)$ & $5(29)$ & $75(33)$ \\
$<10$ & $11(8)$ & $4(7)$ & $1(6)$ & $1(6)$ & $17(8)$ \\
Undetected & $35(26)$ & $15(27)$ & $5(26)$ & $9(53)$ & $64(28)$ \\
\hline
\end{tabular}

and administrative failures in tracking patients. Sixteen patients died before having anti-HBs checked and titres were unavailable in four other patients due to intercurrent illness.

One hundred and forty six patients (64\%) seroconverted after primary vaccination, but only 71 of these $(31 \%)$ reached an anti-HBs titre of $>100 \mathrm{IU} / \mathrm{l}$. The seroconversion rate was similar in haemodialysis (66\%; 90/136), peritoneal dialysis $(66 \% ; 36 / 55)$, and predialysis patients $(68 \% ; 13 / 19)$, but was lower in transplant patients $(41 \% ; 7 / 17) ; \mathrm{p}=0.227$ (table 2 ). Patients who seroconverted after the primary vaccination course tended to be younger (mean (SD) age 54 (18) years $v 60$ (15) years, $p=0.01)$, and had higher levels of serum albumin (mean (SD) 39 (4) $v 38(4), \mathrm{p}=0.025$ ).

A first booster was given to $115 / 156$ patients $(74 \%)$ (table 3). Sixty six patients ( $57 \%$ ) increased their anti-HBs titre by at least one level after one booster dose; including 16/56 patients $(28.6 \%)$ with new seroconversion. Another 43 patients (37\%) were unchanged, and six patients $(5 \%)$ had a fall in anti-HBs. Twenty patients $(31 \%)$ received a second booster dose out of 65 patients in whom it was indicated. Improvement in anti-HBs titre by at least one level was seen in eight $(40 \%)$ patients

Table 3 Uptake and effects of the first two booster doses of the hepatitis B vaccine; values are number (\%)

\begin{tabular}{lll}
\hline & 1 st Booster & 2nd Booster \\
\hline Booster uptake & $115 / 156(74)$ & $20 / 65(31)$ \\
Anti-HBs titre after booster dose & \\
Improved & $66^{*}(57.4)$ & $8 \dagger(40)$ \\
Unchanged & $43(37.4)$ & $9(45)$ \\
Worse & $6(5.2)$ & $3(15)$ \\
\hline
\end{tabular}

* 16 new seroconversions; †five new seroconversions.

\begin{tabular}{|c|c|c|c|c|}
\hline \multirow{2}{*}{$\begin{array}{l}\text { Anti-HBs titre after } \\
\text { primary vaccination } \\
\text { (IU/I) }\end{array}$} & \multicolumn{4}{|c|}{ Follow up titre (IU/I) } \\
\hline & $>100$ & $10-100$ & $<10$ & Undetected \\
\hline$>100(n=90)$ & 33 & 39 & 1 & 17 \\
\hline $10-100(n=25)$ & - & 11 & 1 & 13 \\
\hline
\end{tabular}

(including 5/10 new seroconversions); anti-HBs was unchanged in nine $(45 \%)$ patients, while three $(15 \%)$ had a fall in anti-HBs.

Follow up anti-HBs titres were obtained from 115 patients who had achieved full (anti-HBs titre $>100 \mathrm{IU} / \mathrm{l}, \mathrm{n}=90$ ) or partial immunity (anti-HBs titre 10-100 IU/l, $\mathrm{n}=25$ ), after a mean of 16 months (range 11-25) (table 4). Fifty seven patients $(63 \%)$ with a previous anti-HBs titre of $>100 \mathrm{IU} / \mathrm{l}$ had a reduction in anti-HBs of at least one group, including 17 patients (19\%) who lost all detectable antibody. Anti-HBs antibodies were undetected in 13 out of 25 patients (52\%) with a postvaccination anti-HBs titre of 10-100 IU/l.

\section{DISCUSSION}

There is an inverse relation between the risk of HBV infection after exposure and the maximal anti-HBs response to vaccination, ${ }^{7}$ with anti-HBs titre of $>100$ IU/l conferring very effective protection. ${ }^{89}$ Various protocols for HBV vaccination report seroconversion rates of around $77 \%^{9}{ }^{10}$; reinforced intradermal administration is an alternative effective policy. ${ }^{11}$ We chose a relatively intensive schedule because of the need to protect patients as rapidly as possible. The overall seroconversion rate using this protocol was $64 \%$. There was significant benefit from repeated booster doses, even when the initial response was partial or absent. No patient received more than two booster doses, but it is likely that further improvement in anti-HBs titres would follow additional booster doses. The optimal management of persistent non-responders is not clear.

Vaccination against hepatitis B infection was first recommended in 1982 for UK renal patients likely to dialyse abroad, ${ }^{12}$ and the UK Renal Association currently recommends vaccinating patients awaiting renal replacement therapy as early as possible, and that "all long term dialysis patients should be immunised against HBV. Those who develop an adequate antibody response should be given a booster dose of vaccine every five years. As there is evidence that nonresponders and poor responders derive some benefit from vaccination, they should be given a booster after one year and every five years thereafter". ${ }^{6}$

The rapid decline in post-vaccination anti-HBs titre in uraemic patients is well recognised. ${ }^{913}$ In our series $17 / 90$ patients ( $19 \%$ ) achieving an anti-HBs titre of $>100 \mathrm{IU} / \mathrm{l}$ had no detectable anti-HBs after a mean of only 16 months; loss of antibody was even greater in patients with partial response to vaccination $(13 / 25,52 \%)$. Some protection against infection may be retained even at low anti-HBs titres, ${ }^{8}$ but a rapid decline in 
protection has substantial implications for administering a vaccination programmes because of the need for regular surveillance of anti-HBs titres and organisation of booster doses in many patients.

Routine vaccination of dialysis patients was practised in only 4/73 haemodialysis units surveyed in 1991, with only one unit routinely targeting predialysis patients. ${ }^{5}$ Between 1987 and 1991, 13 cases of acute hepatitis B infection involving 11 haemodialysis units in the UK were reported; the source of infection was often unclear, but four infections were thought to have been acquired abroad. ${ }^{5}$ It is not known how many UK dialysis units are following the Renal Association recommendations. The perceived low risk of acute hepatitis B infection in the UK dialysis population may be a disincentive to implementing vaccination. Based on the costs involved in our programme, the cost of such a scheme in all UK renal units would be considerable, and maintaining adequate antibody titres would require substantial logistical organisation.

We have illustrated practical difficulties in implementing hepatitis $\mathrm{B}$ vaccination on a large scale in a busy unit, despite considerable administrative and nursing effort. The programme was expensive, with a high opportunity cost in administrative and nursing time. Some units delegate vaccination to general practitioners. In our group, predialysis patients whose hepatitis B vaccination was delegated to general practitioners had the lowest vaccine uptake rate $(31 \%)$.

We recognise that a number of dialysis patients run a high risk of hepatitis B infection because of their lifestyle and during foreign travel, both within and outside Europe. In many units non-immune, HBsAg negative patients who dialyse abroad are routinely dialysed in isolation for six months on return to the UK. Vaccination against hepatitis B infection of high risk dialysis patients could save both the patient and the dialysis programme a lot of inconvenience.

In conclusion, stringent application of "universal precautions" prevents transmission of hepatitis B infection within a dialysis unit. Vaccinating all dialysis patients against hepatitis $B$ is logistically difficult. The cost effectiveness of vaccination will vary according to the population at risk. Where routine hepatitis B vaccination of all patients is to be implemented, yearly antibody checks will be required with booster doses administered when anti-HBs titres fall below $100 \mathrm{IU} / \mathrm{l}$.

\section{ACKNOWLEDGEMENTS}

We would like to thank Dr R E Meigh, consultant microbiologist with interest in virology, Department of Virology in Hull public health laboratory for his help in the planning of the vaccination scheme. We also thank the nursing staff on the renal ward and on the dialysis units at Hull Royal Infirmary, Brigg and Scarborough, MLSOs of the virology laboratory, and Debra Dyble for her administrative help.

\section{Authors' affiliations}

K Bel'eed, M Wright, D Eadington, M Farr, L Sellars, Department of Renal Medicine, Hull and East Yorkshire Hospitals NHS Trust, Hull, UK

\section{REFERENCES}

1 Snydman DR, Bregman D, Bryan JA. Haemodialysis associated hepatitis in the United States, 1974. J Infect Dis 1977:135:687-91.

2 Shusterman N, Singer I. Infectious hepatitis in dialysis patients. Am J Kidney Dis 1987;9:447-55

3 Szmuness W, Prince AM, Grady GF, et al. Hepatitis B infection, a point-prevalence study in 15 US haemodialysis centers. JAMA 1974;227:901-6.

4 Geerlings W, Tufveson G, Brunner FP, et al. Combined report on regular dialysis and transplantation in Europe, XXI, 1990. Nephrol Dial Transplant 1991;6(suppl):5-29.

5 Jibani MM, Heptonstall J, Walker AM, et al. Hepatitis B immunisation in UK renal units: failure to put policy into practice. Nephrol Dial Transplant 1994:9:1765-8

6 Renal Association Standards Subcommittee. Treatment of adult patients with renal failure: recommended standards and audit measures. 2nd Ed. London: Royal College of Physicians, November 1997: 64-5.

7 Hadler S, Francis D, Maynard J, et al. Long-term immunogenicity and efficacy of hepatitis B vaccine in homosexual men. N Engl J Med 1986;315:209-14

8 Eddleston A. Modern vaccines: hepatitis. Lancet 1990:335: 1 142-5.

9 Navarro JF, Teruel JL, Mateos ML, et al. Antibody level after hepatitis B vaccination in haemodialysis patients: influence of hepatitis $C$ virus infection. Am J Nephrol 1996;16:95-7.

10 Peces R, de la Torre M, Alcazar R, et al. Prospective analysis of the factors influencing the antibody response to hepatitis $B$ vaccine in haemodialysis patients. Am J Kidney Dis 1997;29:239-45.

11 Propst T, Propst A. Reinforced intradermal hepatitis B vaccination in haemodialysis patients is superior in antibody response to intramuscular or subcutaneous vaccination. Am J Kidney Dis 1998;32:1041-5.

12 Report of the Advisory Group in Hepatitis. Hepatitis B vaccine, guidance on use. London: Department of health and social security, 1982. (CMO (82) 13, appendix 1.)

13 Buti $M$, Viladomiu L, Jardi R, et al. Long-term immunogenecity and efficacy of hepatitis B vaccine in haemodialysis patients. Am J Nephrol 1992;12:144-7. 